\title{
Badania gier wideo z perspektywy edukacji medialnej. Analiza i rekomendacje
}

Video games research from the perspective of media education: Analysis and recommendations

\section{Damian Gatuszka, Agnieszka Taper}

Instytut Socjologii UJ | Centrum Profilaktyki Społecznej

d.a.galuszka@gmail.com | ORCID: 0000-0001-5184-0737

agnieszka.taper@gmail.com | ORCID: 0000-0002-3147-7448

\begin{abstract}
The article presents an analysis of popular reports dealing with the issues of video games and related phenomena; the authors focus on family and parenting issues. The needs and expectations of media educators are the starting point for the analysis. Theoretical assumptions, content, methodology and practical aspects of selected studies are taken into consideration in the analysis. Conclusions are presented as proposals for changes in further research on video games, including their place in the family environment or peer groups.
\end{abstract}

Keywords: video games, media literacy, media education, media competencies, family 



\section{Wprowadzenie}

Niniejszy artykuł jest wynikiem obserwacji roli gier wideo w projektach z zakresu edukacji medialnej. Jako osoby aktywne na polu akademickim, warsztatowym i szkoleniowym mamy okazję przygotowywać zajęcia edukacyjne dla szkół czy też opracowywać materiały naukowe bądź dydaktyczne, dlatego często korzystamy z różnego rodzaju raportów związanych z branżą gier wideo (statystyk, analiz demograficznych itp.). Spostrzeżenie, że wiele z takich dokumentów nie uwzględnia gier wideo jako elementu edukacji medialnej czy też rodzinnej formy wspólnego spędzania czasu wolnego, stanowiło dla nas impuls do pogłębionej analizy zawartości raportów, po które sięgają edukatorzy medialni w toku swojej pracy. Dodatkową motywacją była też chęć przełamania „kołtuństwa" (ang. philistinism) groznawstwa, o którym wspomina Ian Bogost (2015). Chodzi tu o rzadkie łączenie unaukowionego zainteresowania grami wideo z innymi kontekstami życia jednostkowego czy społecznego. Próbujemy przeciwstawić się tej tendencji, łącząc przedmiot zainteresowania ludologii z tematyką właściwą dla innych obszarów wiedzy: edukacji medialnej i socjologii rodziny. Badamy również związek praktyki grania (rozumianej jako forma spędzania czasu wolnego) z kontekstem życia rodzinnego, tak istotnego dla procesu uspołecznienia (tj. socjalizacji) jednostki.

Naszym zamiarem badawczym jest nie tyle krytyka wybranych raportów czy ich autorów, ile skonfrontowanie dotychczas przyjmowanych perspektyw badawczych i ich narzędziowych konceptualizacji z realiami życia rodzinnego i funkcjonowania gier wideo w rodzinach, znanymi nam z własnej praktyki warsztatowo-edukacyjnej i badawczej. Efekt, na jaki liczymy, ma wymiar nie tylko dyskursywny, ale i praktyczny, ponieważ mamy nadzieję, że autorzy kolejnych badań - całkowicie skupionych na rodzinnych aspektach funkcjonowania gier wideo czy też częściowo podejmujących takie wątki - zwrócą uwagę na przedstawiane przez nas rekomendacje badawcze. Wydaje nam się to ważne nie tylko dla odbiorców takich badań, czyli edukatorów medialnych lub osób współpracujących z rodzinami (nauczycieli, pedagogów, bibliotekarzy, przedstawicieli instytucji kultury etc.), ale też dla samych badaczy. Zagadnienia $\mathrm{z}$ dziedziny growej kontroli rodzicielskiej czy szeroko rozumianej growej 
edukacji medialnej podejmowane są w wielu raportach, ale sposób ich poruszania często budzi wątpliwości merytoryczne.

Nasze omówienie określa obecnie dominujący zakres podejmowanych zagadnień badawczych, wskazuje na najpoważniejsze błędy metodologiczne, a także zawiera propozycje dodatkowych zagadnień i założeń badawczych, które mogą zostać podjęte przyszłości.

\section{Gry wideo w kontekście edukacji medialnej i projektów edukacyjnych}

Edukacja medialna, jedna z najmłodszych dziedzin pedagogiki, jest dyscypliną rozwijającą się niezwykle dynamicznie ze względu na tempo rozwoju nowoczesnych technologii i z tego powodu pełni ważną funkcję $\mathrm{w}$ realiach społeczeństwa informacyjnego. Wśród badaczy nie ma konsensusu co do przedmiotu i sposobów prowadzenia projektów z dziedziny edukacji medialnej, jeśli chodzi o dostosowanie ich treści i metod do potrzeb różnorodnych odbiorców (w różnym wieku, z odmiennych środowisk i o innych potrzebach); nie ma także zgody w kwestii definiowania kompetencji medialnych (zob. Ptaszek, 2014; Boyd, 2017; Stunża, 2017). W naszych rozważaniach przyjęliśmy za Bronisławem Siemienieckm definicję edukacji medialnej jako wychowania do krytycznego i świadomego korzystania z mediów, przy czym rolą edukatora jest kształcenie postaw i umiejętności użytkowników, czyli rozwój ich kompetencji medialnych (Siemieniecki, 2007, s. 137). Tę definicję chcielibyśmy jednak uzupełnić o postulaty autorów artykułu Edukacja medialna jako kapitał społeczno-kulturowy w społeczeństwach wiedzy. Twierdzą oni, że nowoczesna edukacja medialna musi nie tylko budować umiejętność krytycznego korzystania z mediów, ale też być interdyscyplinarna, brać pod uwagę możliwości (poznawcze, emocjonalne i społeczne) odbiorców, mieć charakter stosowany (pomagać w rozwijaniu różnych kompetencji); powinna również korespondować ze zjawiskami współczesnej kultury medialnej (Filiciak i in., 2015, s. 225), a takowym bez wątpienia są gry komputerowe.

Szukając nawiązań do gier wideo w polskich katalogach kompetencji cyfrowych, wzięliśmy pod uwagę następujące dokumenty: przygotowany przez Fundację Nowoczesna Polska katalog Cyfrowa Przyszłośc. Katalog 
kompetencji medialnych $i$ informacyjnych (Dąbrowska i in., 2012), kolejną wersję z 2014 roku (Budzisz i in., 2014) oraz Ramowy katalog kompetencji cyfrowych (Jasiewicz i in., 2014). Niestety w wymienionych katalogach nie znaleźliśmy zbyt wielu odniesień do gier wideo; zaryzykujemy nawet stwierdzenie, że gry są w nich traktowane ogólnikowo i marginalnie (przykładowo według autorów młodsi użytkownicy powinni: wiedzieć, że występują gry płatne; umieć samodzielnie wybrać sobie grę; mieć świadomość, że gry mogą „uzależniać”). Jedynie w Ramowym katalogu... w dziale „Relacje z bliskimi” znajdujemy istotną ze względu na rodzinny aspekt gier wideo informację, że rodzic powinien umieć skonfigurować funkcję kontroli rodzicielskiej na konsoli i umieć ocenić, czy dana gra jest odpowiednia dla dziecka (Jasiewicz i in., 2014, s. 17). Zatem z tak ważnych dla praktyków dokumentów - mających z założenia przedstawiać dość szczegółowy zakres kompetencji medialnych - o grach wideo odbiorcy dowiedzą się niewiele. Stąd też powstaje konieczność sięgania po innego rodzaju źródła wiedzy, między innymi raporty. Część z nich została przez nas przeanalizowana pod kątem przydatności w działaniach edukacyjnych, czego efekty przedstawiamy w kolejnej sekcji.

\section{Dobór dokumentów do analizy}

Przedstawione poniżej opracowanie jest przykładem wtórnej analizy danych, ponieważ odwołujemy się do wyników wcześniej zrealizowanych badań, których efektem było wypracowanie oficjalnych dokumentów aktuarialnych, czyli raportów (Frankfort-Nachmias, Nachmias, 2001, s. 321). Wybór metody badań, tematyki oraz typu dokumentów wynika wprost z problemu badawczego, mianowicie pytania o to, jaki rodzaj wiedzy o rodzinnym aspekcie funkcjonowania gier wideo jest przekazywany w popularnych raportach i analizach naukowych, po które mogą sięgać osoby zaangażowane w polskie projekty edukacyjne. Tak postawiony problem wymaga ustalenia cech przekazów i możliwych przyczyn ich formułowania, a także wyprowadzenia wniosków o ich nadawcach, co wpisuje się w podstawowe zastosowania techniki analizy treści (Frankfort-Nachmias, Nachmias, 2001, s. 344). Dokonany dobór dokumentów ma charakter celowy, co oznacza, że zrealizowane badanie nie 
jest reprezentatywne, a jego potencjał eksplanacyjny ogranicza się do przeanalizowanego zbioru.

Przyjęte zasady selekcji miały możliwie wiarygodnie odzwierciedlać sposób poszukiwania wiedzy o grach wideo przez osoby zainteresowane edukacyjnymi, rodzinnymi bądź wychowawczymi aspektami funkcjonowania tego medium. Dlatego też postanowiliśmy rozpocząć od wstępnego wyszukania interesujących nas opracowań poprzez wpisywanie w wyszukiwarce Google fraz, które wskazywałyby na analizy gier wideo i branży elektronicznej rozrywki w powiązaniu z rodziną (hasło „gry wideo rodzina raport”), edukacją (hasło „gry wideo edukacja raport"), wychowywaniem (hasło "gry wideo wychowywanie raport"), szkołą (hasło „gry wideo szkoła raport”) czy socjalizacją (hasło „gry wideo socjalizacja raport"). W przypadku tekstów anglojęzycznych schemat był identyczny, wpisywaliśmy jednak angielskie odpowiedniki przedstawionych w nawiasach haseł. Następnie lista wyszukanych plików została poszerzona o opracowania, które znaliśmy już z dotychczasowej pracy naukowej oraz warsztatowo-edukacyjnej. Odnalezione w ten sposób opracowania poddaliśmy dodatkowej weryfikacji (polegającej m.in. na sprawdzeniu, czy uzyskany tekst zawiera przynajmniej część z interesujących nas informacji) i ostatecznie ustaliliśmy listę dwunastu wydawnictw polsko- i anglojęzycznych. Do analizy włączyliśmy przy tym dwadzieścia cztery dokumenty, ponieważ uwzględniliśmy dwanaście edycji opracowania Essential Facts About the Computer and Video Game Industry. Przyjęliśmy następujące kryteria doboru raportów do analizy:

- Metody ilościowej - ponieważ zależało nam na porównaniu własnych doświadczeń z badań jakościowych z opracowaniami o charakterze ilościowym.

- Rzetelności - wyrażającej się poprzez przynajmniej cząstkowe opisanie w tekście przyjętej metodologii, próby badawczej, wykorzystanych wskaźników i ich wartości etc.

- Tematu - interesowały nas raporty poruszające zagadnienia rodzinnych aspektów funkcjonowania gier wideo, np. kontroli rodzicielskiej.

- Dostępności - mając na uwadze realia pracy wielu edukatorów medialnych (np. niedofinansowanie, konieczność inwestowania własnych środków w materiały edukacyjne, brak wsparcia ze strony 
instytucji), znane nam także z własnego doświadczenia, postanowiliśmy odwołać się tylko do raportów darmowych, szeroko dostępnych i możliwych do pobrania ze stron internetowych.

Wybrane raporty dodatkowo podzieliliśmy na dwie podstawowe kategorie: skoncentrowane na grach wideo i częściowo odnoszące się do tych gier. Te pierwsze są dokumentami, po które sięgnęlibyśmy od razu, szukając informacji o tym medium. Te drugie zazwyczaj dotyczą innych kwestii, na przykład korzystania z internetu przez dzieci, ale niekiedy pojawiają się w nich ciekawe wątki growe, często nieobecne w dokumentach z pierwszej grupy. Wyprzedzając nieco tok wywodu, wskazujemy interesujący przykład z branżowo-marketingowego raportu Polska branża gier komputerowych - analiza wizerunku medialnego i świadomości marek polskich producentów gier. Jednym ze wskazanych tu typów graczy są „Rodzinne Edukatorki” - czyli głównie dojrzałe (powyżej 32 roku życia) kobiety (ponad 80 procent), niespecjalnie zaangażowane w kulturę gier wideo (niska wiedza o grach, rzadkie sięganie po gry i ich kupowanie). (Monday PR, 2012, s. 31).

Ostatecznie na liście raportów przeznaczonych do analizy znalazły się następujące opracowania:

Raporty skoncentrowane na grach wideo:

- Essential Facts About The Computer And Video Game Industry (ESA, 2005, 2006, 2007, 2008, 2009, 2010, 2011, 2012, 2013, 2014, 2015, 2016). To coroczny raport powstający na zlecenie Entertainment Software Association (ESA), nieprzerwanie publikowany od 2005 roku na podstawie badania prowadzonego przez grupę badawczą Ipsos. W dalszej części tekstu raporty z tej serii będą skrótowo określane jako Essential Facts.

- Teens, Video Games, and Civics (Lenhart i in., 2008). Jednorazowy raport przygotowany przez amerykańskie centrum badawcze Pew Internet \& American Life Project we współpracy z Fundacją MacArthura.

- Polska branża gier komputerowych - analiza wizerunku medialnego i świadomości marek polskich producentów gier (Monday PR, 2012). Zlecony przez agencję marketingową Monday PR i zrealizowany przez SW Research raport skupiający się na medialnym wizerunku branży elektronicznej rozrywki w Polsce. 
- Videogames in Europe: 2012 Consumer Study (ISFE, 2012a). Ogólnoeuropejska edycja jednorazowego badania zrealizowanego przez Ipsos MediaCT w szesnastu krajach europejskich na zlecenie Interactive Software Federation of Europe.

- Videogames in Europe: 2012 Consumer Study. Poland (ISFE, 2012b). Polska edycja wyżej wspomnianego badania.

- Game Industry Trends 2014 KIDS (NoNoobs, 2014). Raport powstały na podstawie jednorazowego badania zrealizowanego przez agencję badawczą SW Research na zlecenie spółki NoNoobs.

- Kondycja Polskiej Branży Gier Wideo 2015 (Bobrowski, Rodzińska-Szary, Socha, 2015). Raport z drugiej edycji badania zrealizowanego przez Krakowski Park Technologiczny, grupę Onet.pl oraz portal GRY-Online.pl.

Raporty częściowo odnoszące się do gier wideo:

- Miliardy złotych w rękach dzieci (PPJO, 2013). Jeden z wielu raportów przygotowanych przez Polski Program Jakość Obsługi, opublikowany przez grupę VSC - firmę, która ma wieloletnie doświadczenie w badaniach marketingowych, a w szczególności analizach metodą tajemniczego klienta.

- EU Kids Online: Final Report (Livingstone, Haddon, 2009). Końcowy raport z rozbudowanego badania panelowego realizowanego przez kilka lat w London School of Economics and Political Science (LSE).

- Korzystanie z urządzeń mobilnych przez małe dzieci w Polsce. Wyniki badania ilościowego (Bąk, 2015). Raport oparty na badaniu ilościowym przygotowanym przez znaną w polskim środowisku edukacyjnym Fundację Dajemy Dzieciom Siłę (dawniej Fundacja Dzieci Niczyje).

- Rodzice i dzieci wobec zagrożeń dzieci $w$ Internecie (Orange Polska, 2016). Raport z badania przeprowadzonego przez TNS Polska na zlecenie Orange Polska we współpracy z Fundacją Orange i Fundacją Dajemy Dzieciom Siłę - czyli istotnymi instytucjami zaangażowanymi w projekty edukacji medialnej w Polsce.

- Dzieci po szkole - wolne czy zajęte (Squla.pl, 2016). Raport z badania przeprowadzonego przez SW Research na zlecenie platformy edukacyjnej Squla.pl.

Jako podstawową jednostkę analizy wybraliśmy temat, czyli proste zdanie, będące niekiedy członem zdań złożonych czy akapitów (Frankfort-Nachmias, 
Nachmias, 2001, s. 344). W praktyce tematami były fragmenty dokumentów w postaci wykresów, tabel, danych liczbowych czy linijek tekstu. Kodowanie (tzn. przypisanie jednostek analizy do ogólnych kategorii wynikających z treści zgromadzonego materiału) zostało przeprowadzone przy pomocy narzędzia MaxQDA - oprogramowania typu CAQDA (ang. computer assisted qualitative data analysis software), czyli programu komputerowego wspomagającego analizę danych jakościowych. W toku analizy powstało ponad 420 kodów, które następnie przyporządkowano do przynajmniej jednej z 15 wyłonionych indukcyjnie kategorii. W kolejnych sekcjach tekstu przedstawimy generalny obraz i zawartość raportów, krytycznie przeanalizujemy zastosowane metody badawcze oraz podamy sugestie poszerzenia podejmowanej problematyki.

\section{Omówienie najczęściej podejmowanych zagadnień w analizowanych raportach}

W zbadanych dokumentach podejmowano następujące zagadnienia (w kolejności od najczęściej do najrzadziej poruszanego):

Metody nadzoru: chodzi tu głównie o wykorzystywane przez rodziców sposoby kontroli grających dzieci, a także próby ustalenia odsetka opiekunów, którzy zwracają uwagę na rodzaj lub zawartość wykorzystywanych przez dzieci gier wideo. W raportach z cyklu Essential Facts bada się też obecność rodziców podczas zakupów lub pożyczania gier. Ciekawym wątkiem rozpatrywanym w pojedynczych raportach jest zakres i rodzaj kontroli rodziców w zależności od rodzaju medium (gry wideo, telewizja, filmy, internet) i typu urządzenia (komputer, smartfon, tablet, konsola). Na wyróżnienie zasługuje raport GIT 2014 KIDS, w którym zapytano rodziców o powody niestosowania kontroli rodzicielskiej. Taka wiedza daje szanse na poprawę strategii komunikacyjnych wykorzystywanych przez edukatorów medialnych. Wątek kontroli podejmowany był w osiemnastu dokumentach (w tym dwunastu z serii Essential Facts).

Wspólne korzystanie z gier wideo: pytania odnoszące się do tej materii w dużej części dotyczyły powodów wspólnego korzystania z gier wideo, a także prób określenia najczęściej wybieranych przez dzieci towarzyszy 
do grania (zazwyczaj byli to znajomi czy osoby poznane w internecie, rzadziej rodzice lub członkowie rodziny). Pewna sprzeczność pojawia się w analizie danych dotyczących rodziców chętnych do wspólnego grania z dziećmi. W raportach Teens, Video Games, and Civics, Videogames in Europe: 2012 Consumer Study. Poland oraz Dzieci po szkole - wolne czy zajęte podano informacje, które wskazują na niski odsetek rodziców zainteresowanych tą formą spędzania czasu wolnego. Przykładowo w drugim z tych dokumentów (ISFE, 2012a, s. 21) czytamy, że 25 procent polskich rodziców przyznało, że gra ze swoimi dziećmi. Z kolei w GIT 2014 KIDS napisano: „Można powiedzieć, że granie w gry łączy pokolenia. Co piąty badany (19 proc.) gra sam, prawie połowa (46 proc.) gra sama lub z dzieckiem, a 10 proc. gra w gry wideo tylko z dzieckiem" (NoNoobs, 2014, s. 5). Ujawniają się tu istotne rozbieżności w wynikach omawianych badań, co sprawia, że trudno o jednoznaczne wnioski, jeśli chodzi o ważny z perspektywy wychowawczej aspekt wspólnego korzystania z gier wideo. Ponieważ wyników tych nie można ze sobą porównywać (zachodzi tu odmienność przyjętych metodologii, grup badawczych i czasu realizacji badań), zasadne pozostaje pytanie o rzeczywistą skalę opisywanego zjawiska. Wątek wspólnego grania podejmowany był w siedemnastu dokumentach (w tym jedenastu z serii Essential Facts).

Wpływ gier wideo na życie jednostek i rodziny: głównym celem pytań dotyczących tego zagadnienia było określenie wpływu korzystania z gier wideo na rozwój umiejętności i zasobów kompetencyjnych dzieci. W takim ujęciu użytkowanie gier wideo stanowi korelat szerszych praktyk, na przykład wyszukiwania informacji w internecie, rozwijania kreatywności i zainteresowań, wzbogacania wiedzy, budowania relacji z innymi ludźmi. Sprawdzano też, czy obecność gier wideo w rodzinie wpływa na integrację jej członków - także w porównaniu do innych mediów. Warto odnotować fragment raportu EU Kids Online: Final Report, który zwraca uwagę na konieczność takiego projektowania rozwiązań sieciowych (w tym gier online), aby dzieci w toku ich wykorzystywania mogły przechodzić od działań prostszych do bardziej złożonych - rozwijając przy tym własne kompetencje (Livingstone, Haddon, 2009, s. 22). Wątek wpływu podejmowany był w szesnastu dokumentach (w tym dwunastu z serii Essential Facts). 
Znajomość i wykorzystanie systemów ratingu gier: to zagadnienie powiązane $\mathrm{z}$ wątkiem kontroli, ponieważ ocena zawartości gry wideo powinna być stałym elementem wysiłków wychowawczych opiekuna grającego dziecka. Z tego też wynika częste pytanie o rozpoznawalność danego systemu oraz stosowanie się do jego zaleceń. W przypadku badań odnoszących się do realiów amerykańskich, czyli Essential Facts, chodzi o system ESRB (ang. Entertainment Software Rating Board), natomiast w pozostałych raportach pytano o ogólnoeuropejski system klasyfikacji gier PEGI (ang. Pan-European Game Information). W ramach tej kategorii pytano też rodziców o to, czy ich zdaniem dzieci miały styczność z grami przeznaczonymi dla starszych odbiorców - niestety do takich sytuacji dochodzi stosunkowo często (por. ISFE, 2012a, s. 29-30; ISFE, 2012b, s. 26; Lenhart i in, 2008, s. 25). Warto odnotować, że w kilku badaniach pojawiły się próby problematyzacji tego zagadnienia. W obu dokumentach Videogames in Europe pytano rodziców, czy system PEGI powinien być stosowany także do gier mobilnych i społecznościowych. Prócz tego od edycji z 2013 r. w opracowaniach Essential Facts publikowane są statystyki pokazujące odsetek wydanych w USA gier, które otrzymały jedną z kategorii wiekowych ESRB. Podobne dane, ale dotyczące użytkowników, przedstawiono w raporcie Kondycja Polskiej Branży Gier Wideo 2015. Wynika z nich, że największym zainteresowaniem internautów korzystających z popularnego w Polsce portalu GRY-Online.pl cieszą się gry dla dorosłych (kategoria wiekowa PEGI 18), przy czym im niższa kategoria, tym niższe generuje ona zainteresowanie wśród użytkowników serwisu (Bobrowski i in., 2015, s. 37). Wątek systemów ratingowych podejmowany był w jedenastu dokumentach (w tym sześciu z serii Essential Facts).

Gry jako produkt: w ramach tej kategorii pytań sprawdzane było przede wszystkim zaangażowanie rodziców w zakup gier dla dzieci, rzadziej to, czy dzieci same kupują sobie gry. Zastanawiające jest jednak, że tak istotny element podejmowano szerzej tylko w raporcie GIT 2014 KIDS, w którym dodatkowo pytano między innymi o okazje do dawania dzieciom gier, czynniki wpływające na wybór gry, miejsce zakupu i rodzaj kupowanych gier (z promocji lub wyprzedaży; nowe w pełnej cenie; dołączone do czasopism; używane $z$ drugiej ręki), średnie miesięczne wydatki na gry dla dziecka czy czynniki zachęcające do częstszych zakupów gier 
dla dziecka. W tym samym opracowaniu podjęto bardzo istotne zagadnienie zakupu gier z treściami nieodpowiednimi dla dzieci, do czego przyznało się 27 procent ankietowanych rodziców. Deklarowane powody takiego - jak się wydaje, nierozsądnego - zachowania były następujące: błędne oznaczenia gry (30 proc.); brak zwrócenia uwagi na oznaczenia kategorii wiekowej (26 proc.); ignorowanie oznaczenia ze względu na namowy dziecka (21 proc.) lub dobrą opinię o grze (21 proc.); zakup ze względu na namowy sprzedawcy (11 proc.) (NoNoobs, 2014, s. 22). Wątek zakupu gier wideo podejmowany był $\mathrm{w}$ zaledwie pięciu dokumentach (w tym jednym z serii Essential Facts).

Wykorzystywany sprzęt: przedmiotem zainteresowania był też sprzęt elektroniczny, który umożliwia uruchamianie gier wideo. Chodziło przede wszystkim o obecność urządzeń cyfrowych w domu rodzinnym, a rzadziej o charakter ich własności (tylko rodzica, dziecka, współdzielone). Według rozpatrywanych raportów komputer pozostaje główną platformą do gier - szczególnie w Polsce (por. Bąk, 2015, s. 7; Bobrowski i in., 2015, s. 24; Squla.pl, 2016, s. 5) - przy czym obserwowany jest wzrost znaczenia urządzeń mobilnych (smartfonów i tabletów). Wątek sprzętu podejmowany był w czterech dokumentach (w tym żadnym z serii Essential Facts).

Postawy i kompetencje rodziców: tu pytania odnosiły się do potencjału relacyjnego opiekunów grających dzieci, jednak w dość ograniczonym wymiarze. Uzyskiwane dane były pochodną samooceny respondentów w zakresie posiadanej wiedzy o wykorzystywanych przez dziecko grach, określanej na skali nominalnej (np. „Jak ocenia Pan/Pani poziom swoich umiejętności w zakresie..."); być może wyższą rzetelność pomiaru udałoby się uzyskać przy pomocy pytań sprawdzających konkretne umiejętności lub też na podstawie zadań testowych. Starano się także określić charakter stosunku rodziców do gier wideo przy pomocy prostej skali (wpływ pozytywny, neutralny, negatywny) lub też poprzez listę najczęściej kojarzonych z grami słów. Zaobserwowaliśmy pewne próby problematyzacji badanego zagadnienia, czego przykładem może być analiza zróżnicowania w ocenie gier pomiędzy rodzicami chłopców i dziewczynek. Okazuje się - i to może być bardzo istotna wskazówka praktyczna dla edukatorów 
medialnych, a dla naukowców sugestia wartego pogłębienia i sprawdzenia w polskich realiach problemu badawczego - że rodzice dziewczynek są bardziej skłonni wyrazić pogląd o braku wpływu lub neutralnym wpływie gier, natomiast rodzice chłopców częściej ten wpływ zauważają i określają go jako negatywny (Lenhart i in, 2008, s. 39). Podany przykład rozwinięcia omawianej kategorii stanowi jednak wyjątek, a osoby zainteresowane tym zagadnieniem mogą sięgnąć tylko do opracowań naukowych (zob. Gałuszka, 2016). Wątek postaw i zasobów kompetencyjnych podejmowany był w pięciu dokumentach (w tym dwóch z serii Essential Facts).

Czas poświęcany na gry wideo: w tym zbiorze pytań niestety obserwujemy jedynie powierzchowne podejście do zagadnienia. Zazwyczaj brakuje osadzenia wartości bezwzględnych lub przedziałów czasowych w szerszym kontekście (np. planu dnia dziecka czy też relacji między liczbą godzin spędzonych na graniu a czasem poświęconym innym pasjom lub obowiązkom). Co więcej, w każdym z pięciu raportów (nie było wśród nich żadnego z serii Essential Facts) pytano o co innego, stąd znów nie jest możliwe porównywanie wyników. Poza typowymi pytaniami o czas poświęcany na granie sprawdzano też częstość sięgania po gry wideo w porównaniu do innych aktywności realizowanych w czasie wolnym, a także ujmowano granie jako jeden z możliwych celów korzystania z internetu.

Rodzaj gier i sposób korzystania z nich: jest to kategoria, do której zaliczyliśmy pytania o najczęściej wybierane przez dzieci gry lub też gatunki gier. Ogólnie rzecz ujmując, jedyną próbą pogłębienia tego zagadnienia było porównanie częstości grania na urządzeniach mobilnych z bezcelową zabawą i oglądaniem filmów (Bąk, 2015, s. 11) czy dopytanie rodziców o okoliczności udostępniania dzieciom wybranych urządzeń (tamże, s. 13-14). Zaskakiwać może jednak to, że nawet po poszerzeniu analizy o fragmenty raportów, w których autorzy nie odnoszą się w swoich pytaniach tylko do kontekstu rodzinnego - jak przykładowo w Essential Facts czy Videogames in Europe - wątek rodzaju gier i sposobów korzystania $\mathrm{z}$ nich ujawnił się w zaledwie czterech dokumentach, w tym żadnym z serii Essential Facts. 
Każdej z powyższych kategorii udało się przyporządkować przynajmniej dziesięć kodów, ale zidentyfikowaliśmy dodatkowo cztery kategorie marginalne, którym przypisaliśmy łącznie dwanaście kodów. Są to na tyle istotne elementy obecności gier wideo w środowisku rodzinnym, że należy o nich wspomnieć przynajmniej skrótowo. W trzech dokumentach pojawiły się dane o źródłach informacji (chodzi tu zarówno o osoby, jak i rodzaje odwiedzanych mediów) na temat gier - zarówno gromadzonych przez rodziców, jak i dzieci. W dwóch ankietach zapytano o edukacyjny wymiar gier i ich wykorzystanie w szkołach. Jeden dokument zawierał wykresy ukazujące miejsca, w których dzieci korzystają z gier wideo, a także pytanie skierowane do rodziców o rozumienie słów wykorzystywanych przez grające dziecko.

Wśród wytypowanych raportów nie znalazło się opracowanie, które w sposób wyczerpujący, bezsprzecznie rzetelny i powtarzalny opisywałoby kwestię rodzinnego aspektu funkcjonowania gier wideo. Większość dokumentów podejmuje tylko wybrane tematy wynikające z obecności gier wideo w środowisku rodzinnym, a do niektórych raportów można mieć poważne zastrzeżenia metodologiczne. Co więcej, zazwyczaj badacze kierują swoje pytania do jednej strony, czyli rodziców, pomijając głos dzieci. Uważamy to za błąd, ponieważ rodzina to złożony system, w którym „wszystkie elementy są ze sobą powiązane i wzajemnie na siebie oddziałują" (Slany, 2008, s. 103), stanowiący jednocześnie podłoże dla wielu zjawisk „o psychospołecznym, psychologicznym czy pedagogicznym charakterze" (Tyszka, 1997, s. 698) i jako całość pełniący liczne funkcje: reprodukcyjną, socjalizacyjną, opiekuńczą, emocjonalną, seksualną, ekonomiczną, stratyfikacyjną, identyfikacyjną, integracyjno-kontrolną czy rekreacyjno-towarzyską (Szlendak, 2010, s. 116-117).

Do przedstawionego powyżej obrazu badań nie przystaje raport Game Industry Trends 2014 KIDS, który całościowo podejmuje zagadnienie rodzinnych aspektów funkcjonowania gier wideo. W dokumencie tym zawarto nie tylko pytania z najpopularniejszych kategorii, ale też zagadnienia niepodejmowane w innych opracowaniach. Niestety, GIT 2014 KIDS należy do raportów wzbudzających poważne wątpliwości względem przyjętej metodologii i sposobu realizacji badania. Tymi kwestiami zajmiemy się w kolejnym fragmencie artykułu. 


\section{Ocena metodologii analizowanych raportów}

W niniejszej części tekstu przedstawiamy zastrzeżenia dotyczące podstaw metodologicznych przeanalizowanych raportów. Okazuje się, że w niektórych przypadkach nie zachowuje się tak ważnej w naukach empirycznych powtarzalności prowadzonych badań. Ponadto pomimo relatywnie dużego zróżnicowania podejmowanych zagadnień wiele zjawisk bada się przy użyciu prostych wskaźników o charakterze deklaratywnym. W dalszej części niniejszej sekcji chcemy przede wszystkim zwrócić uwagę na:

- niewystarczające objaśnienia przyjętych w raportach metodologii;

- wątpliwości związane z doborem, formą oraz zakresem pytań skierowanych do respondentów;

- nasz sceptycyzm związany z przeznaczeniem tych badań.

Z dokonanej analizy wynika, że w większości przypadków autorzy marginalizowali wątek metodologiczny oraz dodatkowe opisy, które pozwalałyby na lepsze zrozumienie prezentowanych w ich raportach danych i wniosków. Wiążemy to z komercyjnymi powiązaniami podmiotów odpowiedzialnych za te opracowania. Zarówno amerykańska Entertainment Software Association, jak i europejska Interactive Software Federation of Europe to organizacje zrzeszające producentów i wydawców gier wideo. Natomiast agencja reklamowa Monday PR, spółka akcyjna NoNoobs, Krakowski Park Technologiczny, portal edukacyjny Squla.pl czy firmy VSC i Orange Polska to podmioty działające głównie na rynkach komercyjnych, dla których dbałość o zachowanie ścisłych reguł metody naukowej nie musi być kwestią zasadniczą. Unaocznia to długa lista zastrzeżeń, z których omówimy tylko te najważniejsze:

Brak podstawowych informacji, takich jak sposób doboru próby, charakterystyka wykorzystanych narzędzi badawczych czy metoda opracowania zgromadzonych danych. Zazwyczaj te elementy metodologii są przedstawiane w sposób zbyt skrótowy i lakoniczny. Przykładowo w raportach z serii Essential Facts (zob. ESA, 2005, s. 1) autorzy poświęcają im zaledwie krótki akapit, z którego dowiadujemy się o podmiocie odpowiedzialnym za realizację badania (grupa badawcza Ipsos) i rozmiarze próby (w zależności od edycji badania jest to przedział 
1200-4000 amerykańskich gospodarstw domowych). Co prawda pojawia się tutaj adnotacja, iż dane pochodzą z „reprezentatywnych” gospodarstw, które zostały zidentyfikowane jako posiadające jedną lub więcej konsol do gier czy też komputer osobisty, który służy do uruchamiania oprogramowania rozrywkowego. Na tym kończy się opis próby i brakuje informacji o operacie losowania i metodzie doboru. Dopiero w edycji z roku 2014 pojawia się ważne dookreślenie opisu metodologii. $\mathrm{Z}$ dodanego zdania dowiadujemy się o sposobie realizacji badania, który polegał na przebadaniu w gospodarstwie domowym „głów rodziny”, a także osób najczęściej sięgających po gry (ESA, 2014, s. 1). Taki opis rozwiewa nieco wątpliwości, jednak ciągle nie ma tutaj informacji o sposobie gromadzenia danych (wywiad kwestionariuszowy, ankieta internetowa) czy definicji „głowy rodziny” oraz „osób najczęściej sięgających po gry”. Pomija się też tak podstawowe dla badań ilościowych informacje, jak margines błędu statystycznego czy sposób ważenia obserwacji.

Niski potencjał eksplanacyjny, czego efektem jest niemożność uogólniania uzyskanych wniosków na szersze populacje, a w szczególności kategorię rodziców grających dzieci. Wiąże się to bezpośrednio z przyjmowanymi technikami doboru próby badawczej. Przykładem mogą tu być polskie raporty: Polska branża gier komputerowych... czy chwalony wcześniej za kompleksowość Game Industry Trends 2014 KIDS. Ich autorzy informują, że internetowy wywiad kwestionariuszowy zrealizowany był wśród panelistów społecznościowego portalu badawczego StudentsWatch. pl. Niestety, wybór takiej populacji mógł znacznie wpłynąć na prezentowane w badaniu wyniki. Portal StudentsWatch.pl skupia wokół siebie osoby o określonym profilu: internautów posiadających pewien zakres kompetencji cyfrowych (uczestnictwo w badaniach realizowanych na StudentsWatch.pl wymaga rejestracji), prawdopodobnie przynajmniej przeciętnie orientujących się w przestrzeni wirtualnej. Co więcej, portal ten zachęca do rejestracji i wypełniania ankiet poprzez system korzyści i nagród finansowych, a to skutkuje rekomendowaniem tej platformy badawczej przez osoby poszukujące możliwości zarabiania przez internet. Zasadne pozostaje pytanie, czy w takiej populacji znalazły się osoby o słabszych kompetencjach cyfrowych, stanowiące istotną grupę w kontekście problematyki roli gier w życiu rodzinnym. 
Brak możliwości porównywania uzyskanych danych i sprawdzania trendów, co wynika przede wszystkim ze znacznego zróżnicowania przyjętych technik i grup badawczych. Wiąże się z tym problem rozproszenia i fragmentaryczności podejmowanych zagadnień, przez co trudno uzyskać spójny obraz sytuacji w ramach podejmowanego pola badawczego.

Jednostronność perspektywy, co wynika z ignorowania głosu grających dzieci. W zdecydowanej większości dokumentów autorzy zwracali się z pytaniami tylko do rodziców, pomijając przy tym perspektywę dzieci. Jak już zostało wspomniane, rodzina to system, w którym istotną rolę odgrywają różne osoby. Uzyskanie pełnej perspektywy wymagałoby analiz porównawczych i uznania podmiotowości dzieci.

Hermetyczność przejawiająca się brakiem nawiązań do innych badań o podobnej tematyce czy też do szerszej wiedzy teoretycznej. Sporadyczne odwołania przyjmują formę anegdotyczną, na przykład: „Jak tłumaczą socjologowie, rodzice uwzględniają podczas zakupów zdanie dziecka, ponieważ mają silnie zakorzenione poczucie obowiązku zapewnienia mu szczęśliwego dzieciństwa" (PPJO, 2013, s. 2), co podważa wiarygodność takich stwierdzeń i ogranicza możliwość ich weryfikacji.

$\mathrm{Na}$ osobny akapit zasługują raporty EU Kids Online: Final Report; Teens, Video Games, and Civics; Korzystanie z urządzeń mobilnych przez małe dzieci w Polsce. Wyniki badania ilościowego. W każdym zawarty został stosunkowo rozbudowany opis podmiotów odpowiedzialnych za projekt badawczy, celów badania, sposobu doboru próby badawczej i jej charakterystyki, wykorzystanych technik badawczych, podstawowych pojęć użytych w badaniu i sposobu ich pomiaru. W tych dokumentach obecne są też poprawnie opisane odniesienia do szerszej wiedzy teoretycznej czy innych opracowań o charakterze empirycznym, co stanowi ważny wkład w rozwój dociekań naukowych nad interesującą nas tu tematyką. Oba raporty mogą stanowić punkt odniesienia dla kolejnych projektów badawczych z zakresu edukacji medialnej, zwłaszcza tych skupiających się na grach wideo. Ważna jest też krytyczna postawa badawcza, którą ujawnili autorzy raportu Korzystanie z urządzeń mobilnych... Przyznają oni, że ankieta internetowa skierowana do rodziców jest popularną, ale 
jednocześnie nieoptymalną metodą badania medialnych zwyczajów dzieci (tu: korzystania z urządzeń mobilnych), sugerując jednocześnie wykorzystanie triangulacji metod badawczych w postaci łączenia ankiet i obserwacji (Bąk, 2015, s. 6). Zgadzamy się z takim kierunkiem rozwoju badań edukacyjnych, a szczegóły własnej propozycji przedstawiamy w kolejnym fragmencie niniejszego tekstu.

\section{0 konieczności rozszerzenia przyjmowanej perspektywy}

W tym fragmencie chcemy skrótowo przedstawić dodatkowe wątki tematyczne, które naszym zdaniem powinny stać się elementem możliwie kompletnego projektu badawczego podejmującego temat rodzinnych aspektów funkcjonowania gier wideo. Propozycje te wynikają z naszych wcześniejszych badań realizowanych techniką wywiadu pogłębionego z rodzicami grających dzieci (zob. Gałuszka, 2016), rozmów z rodzicami w trakcie spotkań i szkoleń oraz w niewielkim stopniu z przeprowadzonej na potrzeby niniejszego tekstu analizy raportów. Wątki, które wymagają dalszych badań, to:

- poziom kompetencji cyfrowych rodziców grających dzieci;

- zagadnienie braku weryfikacji wiedzy nt. gier przez rodziców, tj. opierania się na domysłach i własnych wyobrażeniach zamiast na lekturze recenzji, opisów lub instrukcji;

- postawy rodziców wobec nowych technologii (na skali pomiędzy technofobią a technooptymizmem);

- osobiste doświadczenie grania a kompetencje wychowawcze rodzica;

- gry wideo w mechanizmach karania i nagradzania;

- rówieśnicza, w tym cyfrowa, dystrybucja gier poza świadomością opiekunów;

- dziecko jako pośrednik (gatekeeper) między rodzicami a światem gier wideo;

- ograniczenia lub brak komunikacji pomiędzy dzieckiem a rodzicem w kontekście gier wideo;

- unikanie wspólnego korzystania z gier;

- gwałtowny i wczesny rozwój growy dzieci;

- zinternalizowane schematy konsumpcji mediów a gry wideo;

- gry sieciowe i wspólne granie z obcymi; 
- gra w funkcji „cyfrowej niani”;

- niepokojące zachowanie dziecka w trakcie rozgrywki;

- gry wideo w procesie nabywania kompetencji cyfrowych u dzieci i dorosłych;

- pozacyfrowe formy rozwijania pasji do gier wideo, w tym nowe sposoby partycypacji w kulturze gier komputerowych;

- rola growych preferencji i gustu w procesie budowania relacji pomiędzy rodzicem a dzieckiem;

- wpływ przekazów marketingowych na politykę zakupu gier w rodzinie;

- charakter wsparcia dla rodziców ze strony instytucji (w tym szkoły) w sprawach związanych z wykorzystywaniem gier przez dziecko;

- kwestia realnej pomocy (rozumianej jako oferta edukacyjno-szkoleniowa, obecność instytucji i organizacji) w wyżej wymienionym zakresie dla rodzin zamieszkujących obszary nisko zurbanizowane i peryferyjne.

Reasumując, pozwalamy sobie wypunktować cechy dobrze przygotowanego badania, które dostarczyłoby edukatorom medialnym - ale też nauczycielom, pedagogom i innym profesjonalistom współpracującym z rodzinami - rzetelnej wiedzy o grach wideo w kontekście życia rodzinnego:

- Reprezentatywność - dbałość o wyniki, które dawałyby rzetelną odpowiedź na pytanie o charakter rodzinnych aspektów funkcjonowania medium gier wideo. Respondentami byliby nie tylko rodzice, ale też dzieci i nauczyciele oraz inne osoby, które są istotne w procesach wychowania i socjalizacji (dziadkowie i babcie, pracownicy bibliotek, pedagodzy szkolni etc.).

- Powtarzalność - próba ujęcia zasadniczych problemów i zjawisk w jednym, okresowo powtarzanym badaniu (opartym na rzetelnej, względnie stałej i dobrze opisanej metodologii), będąca formą przeciwdziałania rozproszeniu analiz, a także dająca możliwość przewidywania trendów i lepszej obserwacji zmieniających się zwyczajów związanych z obecnością gier wideo w życiu polskich rodzin.

- Kompleksowość - poszerzenie badań na obszary edukacji pozaformalnej (stowarzyszenia, fundacje etc.) oraz formalnej (szkoła a gry wideo), a także wzbogacenie ich o wyżej przedstawione wątki tematyczne. 
Przedstawiony artykuł to przede wszystkim próba krytycznego spojrzenia na dotychczas opublikowane raporty, które podejmują zagadnienie gier wideo i towarzyszących im zjawisk. Jest to jednak dopiero pierwszy krok, ponieważ zasadniczy cel naszej pracy wciąż czeka na realizację. Chcielibyśmy, aby nasza publikacja stała się przyczynkiem do powstania projektu badawczego przeprowadzonego - przynajmniej w jakiejś części - zgodnie z wyżej nakreślonymi wytycznymi. Jednocześnie liczymy, że niniejszy tekst stanie się pretekstem do dyskusji i współpracy w szerszym gronie - także przy zaangażowaniu polskich badaczy gier - a także inspiracją dla autorów kolejnych przedsięwzięć naukowych powiązanych z podejmowanymi tutaj wątkami i obszarami badawczymi. Mamy nadzieję, że zaprezentowana analiza stanowi przekonujący argument za tezą o niedostatecznym przebadaniu pola powstałego na przecięciu kultury gier komputerowych i życia rodzinnego. Znaczenie gier wideo we współczesnej kulturze daje podstawy do traktowania tego medium jako nowego czynnika socjalizacji, a także przestrzeni intensywnych interakcji i rozwoju jednostek. Należy więc wypracować takie narzędzia, które pozwolą nam na rzetelny opis tego fragmentu rzeczywistości społecznej.

\section{Literatura}

Bąk, A. (2015). Korzystanie z urządzeń mobilnych przez małe dzieci w Polsce. Wyniki badania ilościowego. Online: <http://www.mamatatatablet.pl/ pliki/uploads/2015/11/Korzystanie_z_urzadzen_mobilnych_raport_ final.pdf $>$.

Bobrowski, M., Rodzińska-Szary, P., Socha, M. (2015). Kondycja Polskiej Branży Gier Wideo 2015. Online: <http://www.kpt.krakow.pl/wp-content/uploads/2015/o9/Raport_A4_Web.pdf>.

Bogost, I. (2 lutego 2015). Game Studies, Year Fifteen. Notes on Thoughts on Formalism. Online: <http://bogost.com/writing/blog/game-studies-year-fifteen/>.

Boyd, D. (5 stycznia 2017). Did Media Literacy Backfire? Online: <https:// points.datasociety.net/did-media-literacy-backfire-7418co84d88d\#. h4mecrnv2>. 
Budzisz, W. i in. (2014). Katalog kompetencji medialnych, informacyjnych i cyfrowych. Warszawa: Fundacja Nowoczesna Polska. Online <http:// edukacjamedialna.edu.pl/media/chunks/attachment/Katalog_kompetencji_medialnych_2014_EudBrrI.pdf>.

Dąbrowska, A. J. i in. (2012). Cyfrowa Przyszłość. Katalog kompetencji medialnych i informacyjnych. Warszawa: Fundacja Nowoczesna Polska. Online: <https://nowoczesnapolska.org.pl/wp-content/uploads/2012/05/ Cyfrowa-Przyszlosc-Katalog-Kompetencji-Medialnych-i-Informacyjnych1.pdf>.

ESA (2005). Essential Facts About the Computer and Video Game Industry 2005. Online: <https://pl.scribd.com/document/125495226/ESA-Essential-Facts-2005>.

ESA (2006). Essential Facts About the Computer and Video Game Industry 2006. Online: <https://library.princeton.edu/sites/default/files/2006. $\mathrm{pdf}>$.

ESA (2007). Essential Facts About the Computer and Video Game Industry 2007. Online: <http://www.org.id.tue.nl/IFIP-TC14/documents/ESA-Essential-Facts-2007.pdf $>$.

ESA (2008). Essential Facts About the Computer and Video Game Industry 2008. Online: <http://www.org.id.tue.nl/IFIP-TC14/documents/ESA-Essential-Facts-2008.pdf>.

ESA (2009). Essential Facts About the Computer and Video Game Industry 2009. Online: <http://www.org.id.tue.nl/IFIP-TC14/documents/ESA-Essential-Facts-2009.pdf $>$.

ESA (2010). Essential Facts About the Computer and Video Game Industry 2010. Online: <http://isfe.eu/sites/isfe.eu/files/attachments/esa_ef_2010. pdf $>$.

ESA (2011). Essential Facts About the Computer and Video Game Industry 2011. Online: <http://isfe.eu/sites/isfe.eu/files/attachments/esa_ef_2011. pdf $>$.

ESA (2012). Essential Facts About the Computer and Video Game Industry 2012. Online: <http://isfe.eu/sites/isfe.eu/files/attachments/esa_ef_2012. pdf $>$.

ESA (2013). Essential Facts About the Computer and Video Game Industry 2013. Online: <http://isfe.eu/sites/isfe.eu/files/attachments/esa_ef_2013. pdf $>$. 
ESA (2014). Essential Facts About the Computer and Video Game Industry 2014. Online: <http://isfe.eu/sites/isfe.eu/files/attachments/esa_ef_2014.pdf>. ESA (2015). Essential Facts About the Computer and Video Game Industry 2015. Online: <http://www.theesa.com/wp-content/uploads/2015/04/ ESA-Essential-Facts-2015.pdf $>$.

ESA (2016). Essential Facts About the Computer and Video Game Industry 2016. Online: <http://essentialfacts.theesa.com/Essential-Facts-2016.pdf>. Filiciak, M., Komorowski, T., Murawska-Najmiec, E., Ogonowska, A., Ptaszek, G., Stunża, G. D. (2015). Edukacja medialna jako kapitał społeczno-kulturowy w społeczeństwach wiedzy. W: A. Ogonowska, G. Ptaszek (red.), Edukacja medialna $w$ dobie wspótczesnych zmian kulturowych, społecznych i technologicznych (s. 225-227). Kraków: Impuls.

Frankfort-Nachmias, Ch., Nachmias, D. (2001). Metody badawcze w naukach społecznych (tłum. E. Hornowska). Poznań: Zysk i Ska.

Gałuszka, D. (2016). Relacja dziecko-rodzic w perspektywie gry komputerowej. Wyniki badania nad obecnością gier wideo w rodzinie. Kultura i Edukacja, 25(1), 197-216.

ISFE (2012a). Videogames in Europe: 2012 Consumer Study. Online: <http:// www.isfe.eu/sites/isfe.eu/files/attachments/euro_summary_-_isfe_ consumer_study.pdf $>$.

ISFE (2012b). Videogames in Europe: 2012 Consumer Study. Poland. Online: <http://www.isfe.eu/sites/isfe.eu/files/attachments/poland_-_isfe_ consumer_study.pdf $>$.

Jasiewicz, J. i in. (2014). Ramowy katalog kompetencji cyfrowych. Warszawa: Ministerstwo Cyfryzacji. Online: < https://mac.gov.pl/files/ramowy-katalog-kompetencji-cyfrowych.pdf $>$.

Lenhart, A. Kahnei, J., Middaugh, E., Macgill Rankin, A., Evans, C., Vitak, J. (2008). Teens, Video Games, and Civics. Online: <http://www.pewinternet.org/files/old-media/Files/Reports/2008/PIP_Teens_Games_ and_Civics_Report_FINAL.pdf.pdf $>$.

Livingstone, S., Haddon, L. (2009). EU Kids Online: Final report. Online: <http://www.lse.ac.uk/media@lse/research/EUKidsOnline/EU\%2O Kids\%20I\%20(2006-9)/EU\%2OKids\%20Online\%2OI\%20Reports/ EUKidsOnlineFinalReport.pdf/>.

MondayPR (2012). Polska branża gier komputerowych - analiza wizerunku medialnego i świadomości marek polskich producentów gier. Online: 
<http://mondaypr.pl/wp-content/uploads/2012/11/Raport-Gamingowy_26102012.pdf>.

NoNoobs (2014). Game Industry Trends 2014 KIDS. Online: <https://swresearch.pl/pdf/Raport_GIT_Kids_2014.pdf >.

Orange Polska (2016). Rodzice i dzieci wobec zagrożeń dzieci $w$ Internecie. Online: <https://fundacja.orange.pl/files/user_files/user_upload/ badania/Rodzice_i_dzieci_wobec_zagrozen_dzieci_w_Internecie_23.09_AKv.pdf>.

PPJO (2013). Miliardy złotych $w$ rękach dzieci. Online: <http://www.jakoscobslugi.pl/UserFiles/File/Raport\%2oPolskiego\%20Programu\%2O

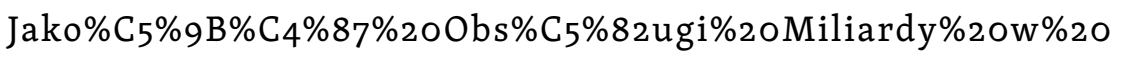
r\%C4\%9gkach\%2odzieci.pdf>.

Ptaszek, G. (2014). Pomiar indywidualnych kompetencji medialnych. Kultura Popularna 3(41), 6-17.

Squla.pl (wrzesień 2016). Dzieci po szkole - wolne czy zajęte. Online: <http:// www.edunews.pl/images/pdf/raport_dzieci_po_szkole.pdf >.

Siemieniecki, B. (2007). Media w pedagogice. W: B. Siemieniecki (red.), Pedagogika medialna. Podręcznik akademicki (tom I). Warszawa: PWN.

Slany, K. (2008). Wpływ urodzenia dziecka na relacje małżeńskie i podejmowane przez małżonków role rodzicielskie. Studia Humanistyczne, 6(1), 103-115.

Stunża, G. (2017). Edukacja kulturalna - podstawa edukacji medialnej. I odwrotnie. Online: <http://edukatormedialny.pl/2017/01/13/edukacja-kulturalna-podstawa-edukacji-medialnej-i-odwrotnie/>.

Szlendak, T. (2010). Socjologia rodziny. Ewolucja, historia, zróżnicowanie. Warszawa: PWN.

Tyszka, Z. (1997). Rodzina. W: W. Pomykało (red.), Encyklopedia pedagogiczna (s. 698). Warszawa: Fundacja Innowacja.

Data dostępu do źródeł internetowych wykorzystanych w tekście: 30 stycznia 2017. 
mgr Damian Gałuszka - socjolog, doktorant w Instytucie Socjologii Uniwersytetu Jagiellońskiego, Kraków

mgr Agnieszka Taper - socjolożka, absolwentka Uniwersytetu Mikołaja Kopernika w Toruniu, edukatorka medialna w Centrum Profilaktyki Społeczne

\section{Badania gier wideo z perspektywy edukacji medialnej. Analiza i rekomendacje}

Abstrakt: Artykuł przedstawia analizę ogólnodostępnych raportów podejmujących zagadnienia gier wideo i towarzyszących im zjawisk, przy czym autorzy skupiają się na wątkach rodzinnych i rodzicielskich. Punkt wyjścia stanowią potrzebyi oczekiwania edukatorów medialnych. Przeanalizowano założenia teoretyczne, treść, metodologię oraz sposób realizacji wybranych badań. Wnioski zostały przedstawione w postaci propozycji zmian w badaniach nad grami z uwzględnieniem ich funkcjonowania w środowisku rodzinnym i rówieśniczym.

Stowa kluczowe: gry wideo, edukacja medialna, kompetencje medialne, rodzina 